\title{
Clínica y ciencia con humanitarismo y ética*
}

\section{Clinic and science with humanitarianism and ethics*}

\author{
Roberto Esguerra • Bogotá, D.C. (Colombia)
}

Quiero compartir unas reflexiones sobre la medicina y en particular sobre nuestra especialidad. Lo primero que me propuse fue encontrar unas palabras que definieran la Medicina Interna de manera integral, así que esas fueron las que escogí para titular esta intervención: "Clínica y ciencia con humanitarismo y ética”. Por primera vez las compartí el pasado 12 de julio, con motivo del día de la Medicina Interna y hoy quiero ante ustedes sustentar su razón de ser.

La clínica definió el origen de nuestra especialidad. La disciplina de la observación cuidadosa y metódica, junto con la habilidad para identificar aquello que para la mayoría pasa inadvertido, y el juicio para relacionar estos hallazgos de una manera lógica con los síntomas y con las patologías, es la destreza que permite al médico clínico identificar y entender las enfermedades.

Esas fueron las habilidades que caracterizaron a los "clínicos", nombre con que se denominó por mucho tiempo a nuestros antecesores, hasta que la escuela alemana incorporó el conocimiento científico estructurado como núcleo central de su formación, para dar sustento sólido a la experiencia clínica, definiendo así el nacimiento de una nueva especialidad: la Medicina Interna, caracterizada por la "actitud científica", que no era común en la medicina de esos años de la segunda mitad del siglo diecinueve.

El nombre de nuestra especialidad comenzó a emplearse desde ese momento y a lo largo del tiempo ha sido motivo de muchas interpretaciones, la más extendida es su referencia a las enfermedades "internas". Sin embargo, para algunos el significado es un poco diferente y está relacionado con el conocimiento científico, que proporciona las herramientas para que el médico pueda "internarse" en la comprensión del organismo humano, así como en el entendimiento de los mecanismos de las enfermedades. Esta interpretación, aunque no es la más aceptada, proporciona una explicación acorde con la evolución y la esencia de la especialidad, para entender que su nombre se deriva de la mirada "interna" que permite la ciencia incorporada a la clínica.

El Diccionario de la Real Academia de la Lengua Española define "humanitario" así: "Que mira o se refiere al bien del género humano", y "humanitarismo" lo define como: "sensibilidad, compasión con las desgracias ajenas". Las dos definiciones de nuestro idioma encarnan la esencia misma de la medicina, el principio de beneficencia el primero y la compasión como elemento de solidaridad el segundo. Por eso pienso que el término "humanitarismo médico" define exactamente el componente humano de nuestra profesión.

Ahora que se ha vuelto un lugar común hablar de "humanización" de la medicina, debemos entenderlo como una invitación para rescatar y hacer evidente aquello que está en la esencia de nuestra profesión. Tengo la impresión de que ese movimiento en la mayoría de los casos no responde a un verdadero sentimiento, sino a la necesidad que impone una nueva moda con evidentes visos comerciales.

La medicina no hay que humanizarla porque la medicina es humana en sí misma. Escapemos a la moda de la humanización e impongamos nuestro sentimiento de servicio humano. Hagamos evidente el altruismo con los seres humanos que están enfermos, permitámosles sentir nuestra comprensión y actuemos de manera espontánea, que transmita la pasión por lo que hacemos. No permitamos que las barreras burocráticas se interpongan entre pacientes y médicos, dando la falsa sensación de que lo que hacemos no es humano.
*Conferencia "Dr. Roberto Esguerra Gutiérrez", dictada durante la inauguración del X Congreso SOLAMI - XXVI Congreso ACMIACP, Cartagena 18 de agosto de 2017. Dr. Roberto Esguerra Gutiérrez. MD. FACP: Especialista en Medicina Interna y Medicina Nuclear. Profesor Clínico Universidad de los Andes. Bogotá, D.C. (Colombia).

Correspondencia: Dr. Roberto Esguerra Gutiérrez. Bogotá, D.C. (Colombia).

E-mail: resguegu@hotmail.com Recibido: 4/X/2017 Aceptado: 19/X/2017 
Resulta exótico hablar de ética en un mundo convulsionado por la corrupción y por la vida carente de un marco ético. Si alguna profesión debe ser modelo de comportamiento ético es la medicina, que desde tiempos inmemoriales se ha caracterizado por las normas de conducta que regulan su práctica. Me atrevo a afirmar que dentro de los médicos, el internista, por su formación, por su concepción holística del ser humano, debe ser paradigma de comportamiento ético. La ética hace parte de nuestro ADN y constituye uno de los pilares esenciales de nuestra especialidad.

En este punto quiero traer a cuento las bellas palabras que pronunció el profesor José Félix Patiño, el pasado 19 de julio, con motivo de la ceremonia de grado de la decimoquinta promoción de médicos de la Universidad de los Andes: "Para ejercer la medicina, para ejercerla

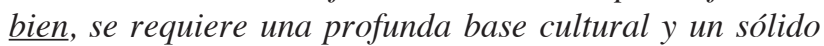
conocimiento intelectual, porque la medicina no es sólo destreza clínica. Es también la observación de valores, de comportamiento, de responsabilidad y, especialmente, es vocación y compasión".

"Clínica y ciencia con humanitarismo y ética" define lo que considero que caracteriza mejor a la medicina interna en el entorno actual. Resalta su sólida estructura que conjuga la fortaleza del conocimiento científico con la sabiduría de la clínica, apoyándolo en el humanitarismo como expresión máxima de acción humana y en la ética como columna vertebral de comportamiento. Vale la pena añadir una virtud en la que hecho énfasis en ocasiones anteriores y a la que el gran William Osler definió como la virtud que debe distinguir al internista: la ecuanimidad.

Dejando atrás estas reflexiones sobre la Medicina Interna, quisiera ahora referirme a papel del médico en la sociedad y al entorno del sistema de salud en nuestro país.

En cuanto al primero me pregunto qué somos y qué representamos actualmente para la sociedad. ¿Es merecedora la profesión médica del respeto y de la admiración que despertaba en el pasado? Es una lástima, pero la respuesta evidente es que no, por lo menos entre nosotros y por lo que he visto, otro tanto ocurre en otras latitudes. En general el médico todavía genera algún respeto al igual que su profesión, pero con menos admiración y con muchas prevenciones.

Percibo que la sociedad no ve en nosotros a las personas generosas que dedicamos nuestras vidas al servicio de los demás, como ocurría hasta hace pocos años. ¡Hoy, en general, se nos mira de la misma manera que a cualquier otro profesional o técnico, pero además en ocasiones se nos cataloga despectivamente como "negociantes" e incluso se llega hasta tildarnos de "mercaderes" que se benefician con el dolor ajeno!

Ya no somos las estrellas que la sociedad veneraba hace unos años. Como profesión hemos perdido el respeto y como individuos hemos perdido la admiración.

Debemos preguntarnos si acaso nos hemos desviado del camino o si será que no tenemos claras nuestras obligaciones, compromisos y responsabilidades. Me parece que hemos dejado de estudiar en la medida en que debiéramos hacerlo. Nos demanda tantas cosas la vida moderna, entre ellas tener un mejor balance que equilibre trabajo, familia y descanso, que es común que no nos quede suficiente tiempo para leer y estudiar, lo que hace que probablemente hoy no somos lo suficientemente cultos y lo adecuadamente sabios.

Además, los médicos vamos perdiendo la disciplina de pensar, la rutina nos envuelve entre sus redes y no nos deja tiempo para lo esencial, simplemente nos permite cumplir con lo necesario. Este no es un asunto menor, si con nuestra responsabilidad y en nuestra situación privilegiada no dedicamos tiempo para pensar, actuaremos simplemente como máquinas, que no hacen nada más allá de producir unos resultados esperados.

Tenemos la obligación de mostrar a la sociedad que podemos ayudar con innovación, mediante la permanente formulación de alternativas para lograr el máximo bienestar de las personas, aportando ideas que guíen los sistemas de salud, para que no siga sucediendo que son los burócratas de turno quienes toman el liderazgo, generalmente sin conocer el problema y más pensando en lo que les interesa como políticos que en lo que requiere la población.

Los problemas de los sistemas de salud invaden el ámbito profesional y ocasionan demandas adicionales de tiempo y esfuerzo. Cuando la burocracia de un sistema no está alineada con la misión de quienes trabajan en él, el conflicto es permanente. Pero los problemas no nos pueden sustraer a nuestra responsabilidad de lograr que el sistema cumpla con su misión, que no es ninguna diferente a la de mejorar la salud de los ciudadanos con los recursos disponibles, lo que nos impone un compromiso ético indeclinable.

El sistema de salud colombiano en sus 24 años de existencia ha alcanzado logros incuestionables como la cobertura prácticamente universal y una enorme disminución de inequidades. Sin embargo, vive una encrucijada difícil de comprender, pues mientras el gobierno muestra como un gran logro lo alcanzado, los prestadores, es decir, médicos, enfermeras, hospitales y clínicas, están sintiendo los rigores de la falta de liquidez, ocasionada por el pago inoportuno o la ausencia total de pago por parte de las EPS.

Un reciente estudio de la Asociación Colombiana de Hospitales y Clínicas (ACHC), muestra que hemos llegado al nivel de cartera más alto en 18 años en que lleva la Asociación haciéndole seguimiento al tema. La deuda con las instituciones que hacen parte de la muestra (que son cerca de $10 \%$ de los prestadores del país) alcanza la descomunal cifra de $\$ 7.3$ billones de pesos. ¿Cómo puede uno entender esa desconexión entre el discurso oficial y la realidad que viven quienes prestan el servicio?

Estamos al borde de un abismo que se hace mucho más profundo con la venta de la EPS Cafesalud, rodeada de toda clase de cuestionamientos e incertidumbres, que se agrega a las liquidaciones de EPS, que han dejado de pagar servicios prestados a lo largo y ancho del país. Que tengamos aprobado el uso medicinal de la marihuana es 
una noticia buena, pero no soluciona los problemas que encuentran los pacientes todos los días para que les autoricen sus tratamientos, como tampoco los importantes avances en la legalización de la eutanasia solucionan las angustias de muchos colombianos por falta de atención médica, ni el control de precios de los medicamentos aleja a los hospitales del peligro de tener que cerrar servicios, ni soluciona a los médicos sus problemas de liquidez debido al retraso en recibir sus honorarios o sus salarios.

Tal vez no sobra recordar que no es posible un sistema de salud sin hospitales, médicos, enfermeras y sin los demás profesionales y técnicos del sector. La sociedad debe sentir a los médicos de su lado, debe percibir su liderazgo, su orientación y su consejo. Es urgente liderar una reforma estructural del sistema que consolide los logros y corrija los problemas, especialmente el del flujo de los recursos.

No hay médico con una mejor formación para afrontar la complejidad que el internista. Eso lo sitúa en una posición privilegiada dentro de la sociedad, no únicamente en su campo profesional en que su importancia es indiscutible, sino que abarca todo el entorno complejo que rodea a la salud y a los sistemas sanitarios. Esa es la razón para que muchos internistas sean lideres reconocidos en el sector, directivos de primer orden en empresas relacionadas con la salud y por supuesto como directores de hospitales y otras organizaciones.

También eso explica el inusitado interés que se observa últimamente entre los estudiantes de pregrado por la Medicina Interna. La verdadera explosión que ha ocurrido en distintas facultades de medicina con la creación de los llamados "Grupos de Interés en la Medicina Interna" o con la sigla IMIG en inglés, con que se les denomina en el ACP; resulta muy interesante pues están integrados por estudiantes que desde muy temprano en su formación quieren conocer más la especialidad, lo que demuestra que están viendo en ella una dimensión, que va más allá del ámbito puramente asistencial.

Como médicos, nuestra obligación no es simplemente con nuestros pacientes y sus familias, tenemos también una responsabilidad con la sociedad, que espera de nosotros ejemplo de comportamiento, que nos mira buscando orientación. En épocas como la que vivimos actualmente en nuestro país, en que cada cual piensa que el mundo gira a su alrededor, en que cada individuo cree que sus derechos no tienen límite alguno y que se puede pasar por encima de los demás sin importar nada, cuando simultáneamente la sociedad carece de un sistema de justicia confiable y ejemplarizante, la vida en comunidad comienza a hacerse imposible.

Es precisamente en estas circunstancias cuando se necesitan ejemplos valerosos que demuestren que la felicidad no radica en hacer todo lo que a uno le gusta y quiere, sino como Aristóteles lo afirma en su ética a Nicomano, "vivir bien y obrar bien es lo mismo que ser feliz". Vivamos bien y obremos bien, demos ejemplo de comportamiento profesional, familiar y social. Demostremos que ser buenos ciudadanos es posible y seamos los médicos quienes demos esa esperanza a una sociedad desorientada y desconsolada.

Agosto de 2017. 